The special issue on the $100^{\text {th }}$ anniversary of Lotfi A. Zadeh (1921-2017)

"Applications of Fuzzy Technology in Civil Engineering and Construction Management"

\title{
PARTICIPANT TRUSTWORTHINESS ANALYSIS IN THE GAME-BASED URBAN PLANNING PROCESSES BY PROMETHEE-MGQNN APPROACH
}

\author{
Romualdas BAUŠYS ${ }^{*}$, Ingrida LEŠČAUSKIENĖ ${ }^{\circledR}$, Rokas SEMĖNAS \\ Department of Graphical Systems, Vilnius Gediminas Technical University, Vilnius, Lithuania
}

Received 11 January 2021; accepted 20 May 2020

\begin{abstract}
Serious games together with the gamified and the game-based surveys (GBS), offer an engaging way to increase citizens' participation in urban planning projects. However, there is always the risk of untrustworthy participants, which can decrease the overall reliability of the game-based research. Trustworthiness analysis is a highly challenging task since the neuropsychology of the GBS respondents and the infinite amount of their possible in-game actions causes many uncertainties in the data analysis. The novel MCDM approach PROMETHEE-mGqNN (PROMETHEE under m-generalised q-neutrosophic numbers) is proposed in this paper as the solution to the described problem. Five criteria that might be automatically calculated from the in-game data are proposed to construct the decision matrix to identify the untrustworthy respondents. The game-based survey "Parkis" developed to assess the safety and attractiveness of the urban public park "Missionary Garden" (Vilnius, Lithuania) is proposed as the case study of this research. By applying the proposed methodology, we calculated the trustworthy index value and noticed that it is capable of detecting the behavioural tendencies of the GBS players.
\end{abstract}

Keywords: MCDM, PROMETHEE, mGqNN, urban planning, game-based research, gamification, public participation, data mining.

\section{Introduction}

Public space planning is a challenging process since the different stakeholder groups are likely to have divergent or even conflicting views on the same projects. Despite the significant changes in the residents' needs, urban planning standards that were developed decades ago are still actively applied. Traditionally, public space planning is formed by the rules and procedures defined on the professional city planners' long-term experience. However, citizens do not want to be observers anymore. They keen to be actively involved in the decision-making affecting neighbouring public spaces (Ampatzidou et al., 2018). Moreover, the earlier in the project management decision-makers become aware of the unsatisfactory decisions, the easier it is to find the most suitable solutions for all the interested groups (Irvin \& Stansbury, 2004).

Public consultations and surveys are the most frequently used methods allowing the decision-makers to gain feedback on the construction projects. Public consultation is an interactive and popular way to gather an in-depth understanding of society opinions. However, since a tiny number of highly motivated people takes part in public consultations, uncertainty related to the citizens' attitude toward the analysed project is especially high. Digital surveys can be chosen as the alternative to public consultations. The rapid spread of the internet created favourable circumstances for the popularity of the online polls; however, recently, the respondent's hesitancy for the traditional surveys has been noticed (Beullens et al., 2018). The decrease in the online polls' response rate can be affected by various reasons, including the amplified number of invitations to fill the survey. The interesting thing is that even though the hesitancy to the online questionnaires increased, citizens' desire to participate in the urban planning projects continues to grow (Czepkiewicz et al., 2017). Therefore, the need for new engaging participatory tools devoted to reflecting citizens' expectations is also growing (Papadopoulos \& Warin, 2007; Stauskis, 2014; Dupuis \& Knoepfel, 2015). For instance, the MIT City Science Group globally develops a CityScope project to facilitate innovative ways for consensus building through participatory processes (Alonso et al., 2018). For illustration, this project's application in Shanghai (China) aims to develop

*Corresponding author. E-mail: romualdas.bausys@vilniustech.lt 
an Urban Decision Support system augmented by artificial intelligence and augmented reality.

Munster et al. (2017) and Falco and Kleinhans (2018) made an extensive review of the digital tools that can be exploited in the modern urban planning processes. Digital participation technologies like Geographic Information Systems (GIS), computer-assisted design (CAD), 3D visualization, remote sensing, global positioning systems (GPS) as well as forums, blogs, social media, video and photo sharing, augmented reality and the virtual worlds can be applied for this purpose. Online communities, discussion forums and blogs are the most popular digital tools that help to integrate expert knowledge and public opinions. However, crowdsourcing, social media-based participatory platforms (Følstad, 2009), neogeography (Foth et al., 2009), Public Participation Geographical Information Systems (Brown, 2017), serious games and gamified surveys (Poplin, 2012; Devisch et al., 2016; Aubert \& Lienert, 2019) are recently emerging as the promising digital tools capable of to engage the community into the urban planning processes. Serious games and gamified surveys might be applied to simulate mechanisms and dynamics of the urban space by relating game components with those existing in real-life environments.

Game-based data collection and analysis are promising ways for participatory modelling due to intrinsic game motivational features and the potential for interactive visualization (Hassan \& Hamari, 2020). This kind of participatory tools can develop an understanding of the complexity of the planning process and create space for experimenting with different ideas without any immediate consequences in the real world. Keusch and Zhang (2017) made a review of game-based and gamified studies. They highlighted that the term "gamified survey" could be used to describe both the "soft gamification" (where the application of virtual badges and other game mechanics is incorporated into the web survey to reduce non-response level) and "hard gamification" (where the entire survey experience is turned into a research game dedicated to collect data from the in-game actions of the respondent who plays the game). In this article, we focus on the gamified surveys that correspond to the concept of hard gamification and call them game-based surveys (GBS).

Results of the classical and game-based surveys are strongly dependent on the trustworthiness of the participants and the chosen data mining strategy. In this paper term "trustworthiness" is understood as the quality of a person that inspires his reliability. Uncertainties related to the inconstant concentration and motivation of the GBS players always accompanies the GBS based data analysis. Moreover, there is always a risk that some of the participants might look at the game-based research nonseriously and play it "for fun". It is especially common if the GBS participants are the volunteers asked to express their opinion. Since data collected from the distracted, non-motivated or even maliciously-minded respondents might cause reliability issues in various stages of the decision-making process, identification of the untrustworthy participants is an important part of any game-based surveys. However, this is a challenging task since some poorquality responses are inevitable even from the highly motivated respondents if they are tired, bored, or distracted by the unpredictable circumstances. This research aims to exclude GBS players who do not seem to provide enough effort from those who perhaps got a little distracted during the play.

GBS involvement in modern public space planning processes can be described by the diagram presented in Figure 1. Participants' trustworthiness analysis is an integral part of the data mining stage called "Data cleaning and validation". Data cleaning and validation is a challenging task in classical surveys and even more demanding in game-based studies (Zhang \& Conrad, 2014).

Different data mining techniques can be employed for the game design validation and the analysis of the players' performance and in-game behaviour. Typically, these goals are achieved by applying visual analysis (Berta \& Moreno-Ger, 2018), supervised and unsupervised algorithms (Owen \& Baker, 2019). Linear models are the most popular amongst the supervised models, while correlation and cluster analysis are common approaches among the unsupervised ones (Alonso-Fernández et al., 2019). The

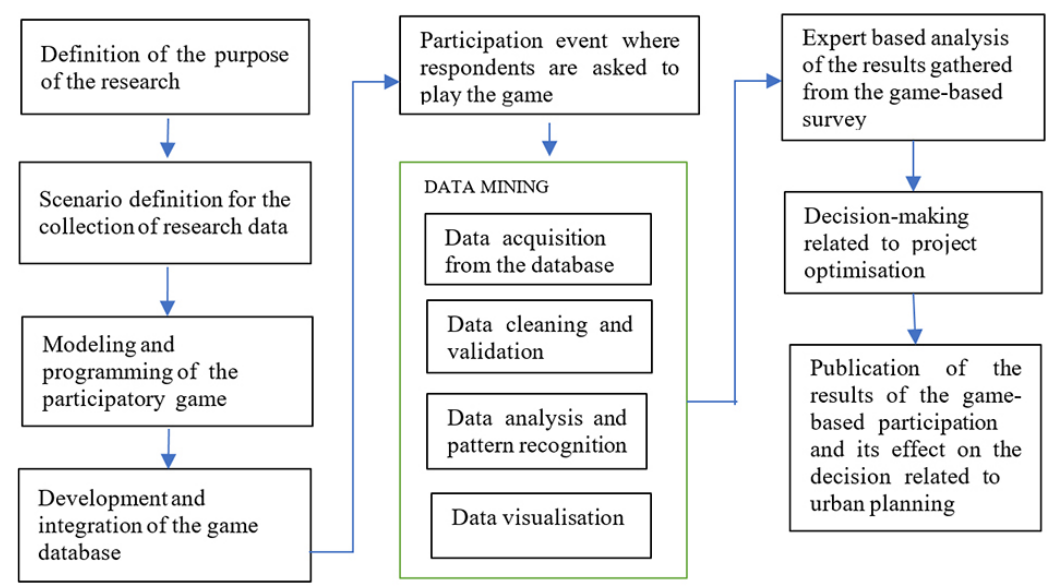

Figure 1. GBS involvement in the modern public space planning processes 
$\mathrm{k}$-means and k-centroids are probably the most popular clustering algorithms in the context of game-based research. However, these techniques split players into several divisions but do not rank them inside clusters.

An ordered K-means clustering algorithm inspired by the multicriteria decision-making approach PROMETHEE (Preference Organization for Enrichment Evaluations method) was recently proposed to solve this issue (Chen et al., 2018). Multicriteria decision making approaches $(\mathrm{MCDM})$ are widely exploited in different contexts. Recently they were applied to assess construction labours' safety level (Mohandes et al., 2020), to rank observation locations for autonomous robot environment exploration tasks (Semenas \& Bausys, 2020), to reflect the psychometric features of the Visual Analogue Scales (Lescauskiene et al., 2020), to increase the accuracy of the checklistsbased quantitative heuristic evaluation (Zavadskas et al., 2021) or to detect edges in satellite images (Bausys et al., 2020). However, there are only a few examples of the MCDM applications in the growing video game industry, and most of them are dedicated to rank the credibility of the e-sport players (Pradhan \& Abdourazakou, 2020; Urbaniak et al., 2020). To the best of our knowledge, there are no studies where MCDM theory would be applied to rank respondents based on their trustworthiness in the game-based studies.

Because of the GBS specifics, a data analysis approach capable of dealing with the uncertainties raised by the player's unpredictability should be chosen for the participants trustworthiness analysis. In the last decade, numerous fuzzy methods have been proposed to consider the vagueness and uncertainties of the initial information. Smarandache (2019) proposed a concept of neutrosophic sets as the generalisation of the classical fuzzy, intuitionistic fuzzy (IFS), q-rung orthopair fuzzy and Pythagorean fuzzy sets. Applying this concept, Zavadskas et al. (2020) extended the MULTIMOORA decision-making approach for the environment of the m-generalized q-neutrosophic numbers (mGqNN).

In this paper, we propose the new PROMETHEE modification capable of working under the environment of the mGqNN sets. PROMETHEE and its variations are frequently chosen for the decision-making tasks related to neuromarketing and behavioural analysis. For instance, Zavadskas et al. (2019a) proposed Neutrosophic PROMETHEE modification for the shopping rent valuation based on potential customers' emotional and physiological states. Chen and Hung (2020) employed PROMETHEE for Personnel Selection Based on Multi-Type Fuzzy Information. This paper aims to propose the PROMETHEE under $\mathrm{m}$-generalized q-neutrosophic numbers (namely PROMETHEE-mGqNN) and its application for the trustworthy analysis of the respondents participating in the game-based survey dedicated to assessing the safety and attractiveness of the urban public park reconstruction project.

The essence of the novel PROMETHEE-mGqNN approach is presented in Section 1. Criteria determined for the trustworthiness analysis is explained in Section 2. The case study representing PROMETHEE-mGqNN application for detection of the non-reliable GBS players is presented in Section 3. Lastly, results and discussion are presented in Section 4.

\section{M-generalised q-neutrosophic PROMETHEE Method}

\subsection{Preliminaries}

M-generalised q-neutrosophic set ( $\mathrm{mGqNs}$ ) is described as $\psi=\{x, \xi(x), \vartheta(x), \eta(x): x \in U\}$, where $\xi, \vartheta, \eta: U \rightarrow[0, r]$ and $(0<r \leq 1)$. The $\xi, \vartheta, \eta$ are the functions, where:

$$
\begin{aligned}
& 0 \leq \xi(x), \vartheta(x), \eta(x) \leq 1 ; \\
& 0 \leq(\xi(x))^{q}+(\vartheta(x))^{q}+(\eta(x))^{q} \leq \frac{3}{m} ; m, q \geq 1 .
\end{aligned}
$$

The functions $\xi(x), \vartheta(x), \eta(x)$ correspond to m-generalised truth membership, m-generalised indeterminacy membership and $\mathrm{m}$-generalised falsity membership. The triplet $\psi=\xi, \vartheta, \eta$ is called $\mathrm{m}$-generalized q-neutrosophic number $\mathrm{mGqNN}$, where $\mathrm{m}$ and $\mathrm{q}$ values can be used to cover different variations of fuzzy sets.

If $\psi_{1}=\xi_{1}, \vartheta_{1}, \eta_{1}$ and $\psi_{2}=\xi_{2}, \vartheta_{2}, \eta_{2}$ are two m-generalized q-neutrosophic numbers defined in the universe set $\mathrm{U}$ and $\lambda$ is any real number $>0$, then the operations between $\mathrm{m}$-generalized q-neutrosophic numbers ( $\mathrm{mGqNN}$ ) are calculated as follows:

$$
\begin{aligned}
& \psi_{1} \oplus \psi_{2}=\left(1-\left(1-\xi_{1}^{q}\right)\left(1-\xi_{2}^{q}\right)\right)^{\frac{1}{q}}, \vartheta_{1} \vartheta_{2}, \eta_{1} \eta_{2} ; \\
& \psi_{1} \otimes \psi_{2}=\xi_{1} \xi_{2},\left(1-\left(1-\vartheta_{1}^{q}\right)\left(1-\vartheta_{2}^{q}\right)\right)^{\frac{1}{q}}, \\
& \left(1-\left(1-\eta_{1}^{q}\right)\left(1-\eta_{2}^{q}\right)\right)^{\frac{1}{q}} ; \\
& \lambda^{*} \psi_{1}=\left(1-\left(1-\xi_{1}^{q}\right)^{\lambda}\right)^{\frac{1}{q}}, \vartheta_{1}^{\lambda}, \eta_{1}^{\lambda} ; \\
& \psi_{1}^{\lambda}=\xi_{1}^{\lambda},\left(1-\left(1-\vartheta_{1}^{q}\right)^{\lambda}\right)^{\frac{1}{q}},\left(1-\left(1-\eta_{1}^{q}\right)^{\lambda}\right)^{\frac{1}{q}} ; \\
& \psi_{1} \ominus \psi_{2}=\left(\left(\frac{\xi_{1}^{q}-\xi_{2}^{q}}{1-\xi_{2}^{q}}\right)^{\frac{1}{q}}, \frac{\vartheta_{1}}{\vartheta_{2}}, \frac{\eta_{1}}{\eta_{2}}\right), \\
& \left(\xi_{1}>\xi_{2} ; \xi_{2}\left\langle 1.0 ; \vartheta_{2}\right\rangle \vartheta_{1} ; \eta_{2}>\eta_{1}\right) ; \\
& \psi_{1}=\left(\frac{\xi_{1}}{\xi_{2}},\left(\frac{\vartheta_{1}^{q}-\vartheta_{2}^{q}}{1-\vartheta_{2}^{q}}\right)^{\frac{1}{q}},\left(\frac{\eta_{1}^{q}-\eta_{2}^{q}}{1-\eta_{2}^{q}}\right)^{\frac{1}{q}}\right), \\
& \left(\xi_{2}>\xi_{1} ; \vartheta_{1}>\vartheta_{2} ; \vartheta_{2}\left\langle 1.0 ; \eta_{1}\right\rangle \eta_{2} ; \eta_{2}<1.0\right) .
\end{aligned}
$$


The ranking between two $\mathrm{mGqNN}$ is performed by the following rules:

$$
\begin{aligned}
& \text { If } S\left(\psi_{1}\right)>S\left(\psi_{2}\right) \text {, then } \psi_{1}>\psi_{2} ; \\
& \text { If } S\left(\psi_{1}\right)=S\left(\psi_{2}\right) \text {, then } \psi_{1}=\psi_{2} .
\end{aligned}
$$

\subsection{PROMETHEE under MGQNN}

This section presents a new extension of the PROMETHEE method developed for the $\mathrm{m}$-generalised q-neutrosophic set environment.

Step 1. Construction of the decision matrix $\mathrm{X}$, which consists of the elements $x_{i j}$, where $i=1,2, \ldots, n ; j=1,2, \ldots, m$. The element $x_{i j}$ represents an estimate of the $i^{\text {th }}$ criterion in the $i^{\text {th }}$ alternative.

Step 2. Normalization of the decision matrix. Vector normalization is applied to get decision matrix $\overline{\mathrm{X}}$, where elements $\bar{x}_{i j}$ is calculated by the equation:

$$
\bar{x}_{i j}=\frac{x_{i j}}{\sqrt{\sum_{i=1}^{m} x_{i j}{ }^{*} x_{i j}}} ; i=1,2, \ldots, n ; j=1,2, \ldots, m .
$$

Step 3. Neutrosophic conversion of the decision matrix $\overline{\mathrm{X}}$. The $\mathrm{m}$-generalised q- neutrosophic decision matrix $\tilde{\mathrm{X}}$ is built from the elements $\tilde{\psi}_{i j}=\left(\tilde{\xi}_{i j}, \tilde{\vartheta}_{i j}, \tilde{\eta}_{i j}\right)$ :

$$
\tilde{X}=\left[\begin{array}{cccc}
\tilde{\Psi}_{11} & \tilde{\Psi}_{12} & \ldots & \tilde{\Psi}_{1 n} \\
\tilde{\Psi}_{21} & \tilde{\Psi}_{22} & \ldots & \tilde{\Psi}_{1 n} \\
\vdots & \vdots & \ddots & \vdots \\
\tilde{\Psi}_{m 1} & \tilde{\Psi}_{m 2} & \ldots & \tilde{\Psi}_{m n}
\end{array}\right] .
$$

Here functions $\xi, \vartheta, \eta$ describe the truth-membership, indeterminacy-membership and falsity membership degree. The functions $\xi, \vartheta, \eta: U \rightarrow[0,1]$ follow the condition $0 \leq \xi(x)+\vartheta(x)+\eta(x) \leq 3$. Elements of the matrix $\overline{\mathrm{X}}$ are converted into neutrosophic numbers $\tilde{\psi}_{i j}$ applying the standard modification rates as in Zavadskas et al. (2017).

Step 4. Ranking of the alternatives by the PROMETHEE method. Comparison between all pairs of $A_{j}$ and $A_{k}$ alternatives are performed by calculating the aggregated preference index $\pi\left(A_{j}, A_{k}\right)$ by the following equation:

$$
\pi\left(A_{j}, A_{k}\right)=\sum_{i=1}^{m} \omega_{i} p_{t}\left(d_{i}\left(A_{j}, A_{k}\right)\right),
$$

where $\omega_{i}$ is the weight of the $i^{\text {th }}$ criterion $\left(\sum_{i=1}^{m} \omega_{i}=1\right)$. The difference $d_{i}$ between two mGqNN numbers $\tilde{\psi}_{i j}$ and $\tilde{\psi}_{i k}$ is calculated as $d_{i}\left(A_{j}, A_{k}\right)=\tilde{\psi}_{i j} \ominus \tilde{\psi}_{i k}$, where $\tilde{\psi}_{i j}$ corresponds to the value of the $i^{\text {th }}$ criterion of the alternative $A_{j}$ and $\tilde{\psi}_{i k}$ corresponds to the value of the $k^{\text {th }}$ criterion of the alternative $A_{k}$. The construction $p_{t}(d)=p_{t}\left(d_{i}\left(A_{j}, A_{k}\right)\right)$ represents the $k^{\text {th }}$ preference function for the $i^{\text {th }}$ criterion selected by the decision-maker from the set of available preference functions. In this study, V-shape preference function (Figure 2) is applied.

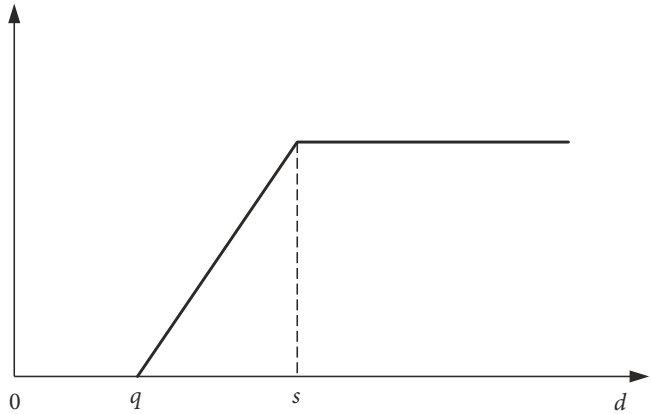

Figure 2. The unicriterion preference function

Step 5. Calculation of the positive outranking flow:

$$
F_{j}^{+}=\sum_{k=1}^{n} \pi\left(A_{j}, A_{k}\right), j=1,2, \ldots n
$$

and the negative outranking flow:

$$
F_{j}^{-}=\sum_{k=1}^{n} \pi\left(A_{k}, A_{j}\right), j=1,2, \ldots n .
$$

Step 6. Calculation of the net flow value $F_{j}$ should be done to determine the final rank of the alternative $A_{j}$ :

$$
F_{j}=F_{j}^{+}-F_{j}^{-} \text {. }
$$

Step 7. Deneutrosophication of the net flow value $F_{j}$. This step is completed by calculating the score value $S\left(F_{j}\right)$ for each of the alternative $A_{j}$ by the following equation:

$$
S\left(F_{j}\right)=\frac{3+3 \xi^{q}-2 \vartheta^{q}-\eta^{q}}{6} .
$$

Remark 2.1. The negative net flow values are calculated applying the additional neutrosophic algebra, which can be expressed as:

$$
F_{j}^{c}=F_{j}^{-}-F_{j}^{+} .
$$

Remark 2.2. For the final interpretation of the PROMETHEE-MGQNN results, the ranking of the alternatives with the positive score value $S\left(F_{j}\right)$ is taken directly (the best alternative has the highest score value), while for the negative score values, the best alternative has the smallest score value.

\section{Criteria for the trustworthiness analysis of the GBS players}

Rational decision-making requires a careful analysis of the decision problem. Since classical surveys provide data in the form of text, numbers and figures, game-based surveys also allow data representing coordinates, trajectories, photos of the visited places or videos of the player behaviour. According to the review by Alonso-Fernández et al. (2019), the most common information collected from the logs of serious games include player choices, written answers, scores, completion times, the overall number of actions and interactions, number of attempts, errors, mistakes, collected items and completed missions, duration of 
the play sessions, player performance, action sequences, progress, location dynamics, player health and the usage of the in-game hints.

Various mixtures of these metrics can be chosen to measure player behaviour in different contexts (Loh et al., 2015). For instance, it is a normal practice for players of entertainment video games to sacrifice some of the game's missions to achieve the "best mission time". However, such a deliberate non-fulfilment of the predetermined missions can be highly undesirable in the game-based surveys. Furthermore, such behaviour of the GBS player might be understood as the lack of motivation to take the GBS seriously. Speeders, straightliners and other respondents with low motivation also can be excluded as the high threat to the reliability of GBS results (Zhang \& Conrad, 2014). However, there is no simple way to identify such participants if they played the game. Visual analysis of player behaviour could be an appropriate approach in addressing the problem analyzed in this paper (Keim et al., 2008). However, since the number of GBS participants can be unpredictable, visual data exploration might become a highly time-consuming task even when the specific software is employed for the data visualisation. Moreover, the combination of several metrics representing the players' in-game behaviour should be analysed to make decisions on the trustworthiness of the respondents. Therefore, it is important to look for solutions that would allow decisionmakers to identify potentially unreliable respondents automatically.

Since the trustworthiness analysis of the GBS players might be understood as the multicriteria decision-making task (MCDM), we propose five numerically measurable criteria and the new multicriteria decision-making approach PROMETHEE - MGQNN as the solution for the problem described in this chapter. The criteria set determined by the authors of this study determined is presented in Table 1.

The criteria set presented in Table 1 is constructed by referencing the player behaviours often noticeable in serious games designed to explore the peculiarities of real-

Table 1. The proposed criteria set and their weights

\begin{tabular}{|c|c|c|c|c|}
\hline Criteria & Optimum & $\begin{array}{c}\text { Criteria } \\
\text { description }\end{array}$ & $\begin{array}{l}\text { SWING } \\
\text { weight }\end{array}$ & $\begin{array}{l}\text { Normalized } \\
\text { weight }\end{array}$ \\
\hline $\mathrm{C} 1$ & MAX & $\begin{array}{l}\text { Game session } \\
\text { time, s }\end{array}$ & 100 & 0.28 \\
\hline $\mathrm{C} 2$ & MAX & $\begin{array}{l}\text { Territory } \\
\text { exploration } \\
\text { time, s }\end{array}$ & 60 & 0.17 \\
\hline $\mathrm{C} 3$ & MAX & $\begin{array}{l}\text { Words in the } \\
\text { open } \\
\text { question, } \\
\text { number }\end{array}$ & 90 & 0.25 \\
\hline $\mathrm{C} 4$ & MIN & Speeding ratio & 80 & 0.22 \\
\hline $\mathrm{C} 5$ & MAX & $\begin{array}{l}\text { Game score, } \\
\text { number }\end{array}$ & 30 & 0.08 \\
\hline
\end{tabular}

world geographical areas. For example, criteria "Game session time" (C1) and "Territory exploration time" (C2) are directly related to the player motivation to delve into the problem analyzed by the game-based surveys. Criterion $\mathrm{C} 1$ defines time interval from the start to the end of the session, including the time required to get acknowledged with the mission's goal or understand the controls of the game. Criterion C2 describes player time spent in the scenarios dedicated to the exploration of the game territory. For instance, $\mathrm{C} 2$ is equal to the total time the player spent in the scenarios S1, S2 and S3 of the GBS presented in this research.

Criterion C3 is determined to represent the total number of dictionary words recorded as the answer to the open question presented in the survey (scenario S4 in Table 2). This criterion is included since poor verbatim responses are a very good indicator of the respondent's decreased motivation. However, even though answers to the openended questions are the easiest ways to identify a poorquality respondent, the gibberish and empty responses are not necessarily the sign of the untrustworthy respondent. In some cases, survey participants do not understand the open question or do not know how to answer it. Therefore, this criterion must be analysed in the context of others.

While a participant who completes the GBS too quickly is also a cause for concern, an additional criterion called speeding ratio (C4) was also determined. The authors of this research proposed to calculate this criterion by the following formula:

$$
R_{n}=\frac{t_{\text {avg }}(S 1)}{t_{n}(S 1)}+\frac{t_{\text {avg }}(S 2)}{t_{n}(S 2)}+\ldots+\frac{t_{\text {avg }}(S k)}{t_{n}(S k)},
$$

where $R_{n}$ is the speeding ratio of the respondent $n ; t_{n}(S k)$ is the time interval that the respondent $n$ spent in the scenario $S k$ and $t_{\text {avg }}(S k)$ is the average time needed to complete scenario $\mathrm{S} 1$. The average is calculated from all the responses of the survey. Only the scenarios without the open questions are analysed to calculate the speeding ratio $R_{n}$.

The final criterion presented for the identification of the untrustworthy respondents is the Game score (C5). Game score directly corresponds to participants performance completing the predefined task. However, this criterion is not so important as it might seem since there is always the risk of the players who want to outwit the system. For example, if a GBS respondent is asked to indicate the three most interesting places in the virtual park, he can quickly mark them all in one small area of this park and still get 100 points for the completion of the task.

Direct weighting criteria elicitation technique SWING (Von Winterfeldt \& Edwards, 1986) was employed to determine the importance of the presented criteria. Three experts representing the decision-makers, game creators and urban planners distantly participated in the consensus-based criteria assessment meeting. The final SWING weights and the normalized weights are presented in Table 1. 


\section{Serious game "Parkis" as the modern urban park planning tool}

Games fostering citizen engagement promote a civic attitude and values by engaging players in the ludic solution of complex civic problems (Battista, 2017). Serious games and game-based surveys can reflect a player's experiences, thus enabling the transference of behavioural patterns between the game and the real world. It is especially useful if there is a need to shift the interests of design and planning processes towards pluralistic and subjective perceptions of space and its use (Foth et al., 2009).

In this research, we present a game-based survey to collect data necessary for the decision making on the urban park planning projects. For this purpose, we have developed a new serious game "Parkis", which is linked to a specific real-world location called "Missionary Gardens" (Vilnius, Lithuania). This historical urban park is located in a central part of Vilnius old town. This area is a part of the former Missionaries monastery founded in the sixteenth century. It is expected that after the proper renovation of the park, the new attractive place will appear for both the tourists and local citizens.

"Parkis" is an offline 3D scenario-based simulator constructed to gather civic insights on the urban park renovation plans (Figure 3). GIS data, building models, trees and other park details (provided in the project plan) were imported into the "Unity 3D" game development platform to represent the territory of "Missionary Gardens". Game scenarios, collision physics, environmental elements and the non-player characters were programmed and implemented by utilising Unity-provided libraries. External SQL database was created to store the information extracted from the participant game sessions.

The game-based survey "Parkis" has been developed at the Department of Graphical Systems at Vilnius Gediminas Technical University (Lithuania) after the partnership with Vilnius City Municipality. Municipal authorities were unsure if the "Missionary Gardens" renovation plan's preliminary design is fully coherent with the local community's needs. Especially client wanted to comprehend if the park presented in the renovation project could be a safe and attractive place for both the citizens and the tourists. Also, they wanted to understand where in this park are the best places for public events.

Since urban public park (UPP) safety and attractiveness are interconnected (Zavadskas et al., 2019b), analysis of "Missionary Gardens" safety and attractiveness was identified as the main objective of this game-based survey. "Parkis" game map (Figure 4) was constructed from the GIS data of the analysed territory and limited to the region that can be reached in 10 minutes walking by foot from the neighbouring urban blocks.

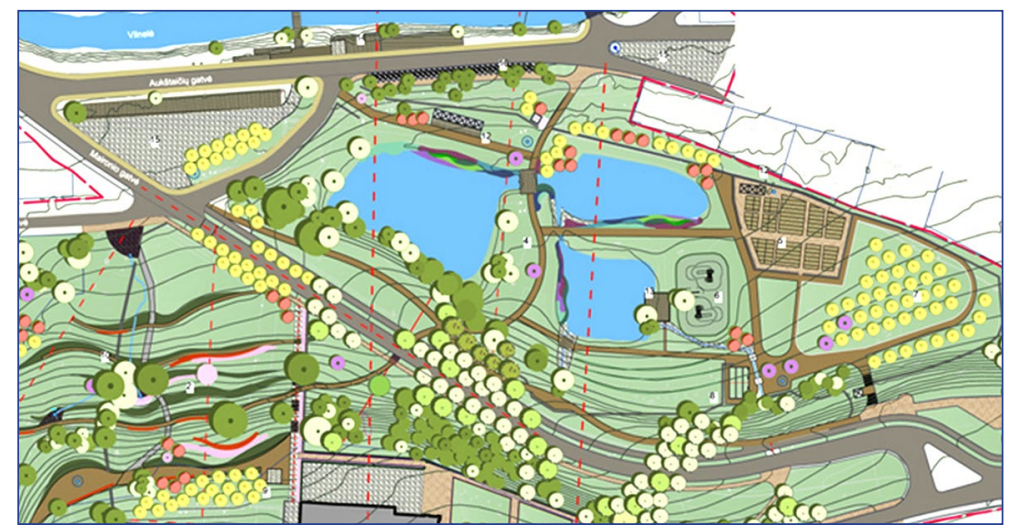

Figure 3. Preliminary design of the renovated public place “Missionary Garden” (source: Vilnius city municipality)
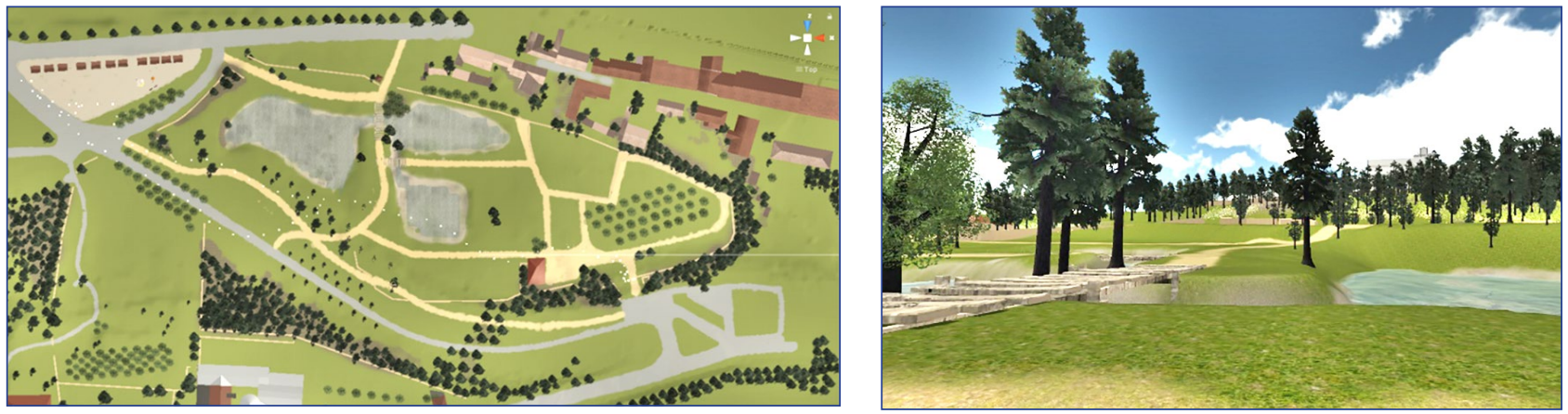

Figure 4. The game field of the game-based survey "Parkis". The game map (on the left side) and the player view (on the right side) 


\subsection{Scenarios for the assessment of urban park safety and attractiveness}

The narrative of the GBS scenarios should be carefully reconsidered when there is a need to search for complex environmental decisions like urban park renovation projects. For instance, if there is a need to get information about the hiding places of the analysed territory, we can simply ask the GBS player to present where the hiding places of this urban park are. However, since this question is highly ambiguous by its nature, such a task might be the reason why the collected responses might be highly subjective and inaccurate. The role-based narrative can be the better choice to collect data about urban park safety. For instance, if the GBS player is playing a scenario where he is acting as a parent who is asked to play "Hide and seek" with his children, there is a high probability that GBS results describing the hiding places will be more accurate. Battista (2017) provided an activity system diagram to illustrate the mediated relationship between scenario subjects, tools, role assignments, rules and the conventions of the participation. He also stated that the narrative of the serious games significantly increases participant's engagement.

Four scenarios (levels) were implemented in "Parkis" to collect data about the "Missionary Gardens" safety and attractiveness (Table 2). These scenarios were created in a way that player movement coordinates, number of hiding places, mission time, answers to the open question and the pictures of the most attractive and the most popular places could be extracted from the game database. In all the scenarios, players had the possibility to explore the park territory before completing the predefined tasks.
At the end of each scenario, a player gets automated feedback on how much time he/she spent at this GBS level and how many points he/she got. Depending on the points collected, the player is also given a specific nomination to increase his short-term motivation to play. After completing each of the scenarios, player data is sent to the game database for further processing. However, as shown in Figure 1, data cleaning and validation must be done before the collected data can be used in the decision-making processes. It is important to do since data collected from these respondents might noticeably affect the reliability of the game-based decisions.

\subsection{Discovery of the untrustworthy respondents: the experiment}

Multicriteria decision analysis is widely used to identify the best employees or the best players of the classical games.

When the scenario-based simulator "Parkis" has been developed and approved by the Vilnius city municipality, it was employed to assess the safety and attractiveness of the urban park "Missionary Garden" renovation project. 86 students living in Vilnius participated in the controlled experiment. All the participants were volunteers who have not played this game until the experiment. During the experiment, participants were not asked to provide their name or surname, only gender and age. Fifty men and thirty-six women between the ages of 20 and 35 years participated in this study.

At the beginning of the experiment, all the participants were acknowledged with the GBS goal. Even though

Table 2. Summary of the implemented scenarios and their characteristics

\begin{tabular}{|c|c|c|c|c|}
\hline Scenario name & Scenario goal & Participant's role & Non-player characters & Data collected \\
\hline $\begin{array}{l}\text { S1. } \\
\text { Hide and seek } \\
\text { scenario }\end{array}$ & $\begin{array}{l}\text { To determine } \\
\text { where are the } \\
\text { unsafe areas of } \\
\text { the park }\end{array}$ & $\begin{array}{l}\text { A player is a local citizen who came } \\
\text { to the park to play with children. The } \\
\text { player has a limited time to find a } \\
\text { hiding place until children start to seek. } \\
\text { Three hiding places must be marked to } \\
\text { get the maximum score of } 100 \text {. }\end{array}$ & $\begin{array}{l}\text { Children who play the } \\
\text { game "Hide and seek" }\end{array}$ & $\begin{array}{l}\text { Player movement paths. } \\
\text { Time spent in the scenario. } \\
\text { Count of the marked hiding } \\
\text { places and their coordinates. }\end{array}$ \\
\hline $\begin{array}{l}\text { S2. } \\
\text { Photographer } \\
\text { scenario }\end{array}$ & $\begin{array}{l}\text { To identify if } \\
\text { the renovated } \\
\text { park could be } \\
\text { an attractive } \\
\text { place for the } \\
\text { tourists }\end{array}$ & $\begin{array}{l}\text { A player is a park visitor who is keen to } \\
\text { help tourist (photographer) visiting the } \\
\text { park. In this scenario, a player has to } \\
\text { search for three beautiful places in the } \\
\text { park and take pictures of them. A score } \\
\text { of } 100 \text { is granted for fully completing } \\
\text { the task. }\end{array}$ & $\begin{array}{l}\text { Tourist who wants } \\
\text { to shoot the most } \\
\text { attractive and the most } \\
\text { popular places of the } \\
\text { park }\end{array}$ & $\begin{array}{l}\text { Player movement paths. } \\
\text { Time spent in the scenario. } \\
\text { Coordinates of the picture } \\
\text { taking place. } \\
\text { Screenshots that represent the } \\
\text { photographed view. }\end{array}$ \\
\hline $\begin{array}{l}\text { S3. } \\
\text { Public } \\
\text { community } \\
\text { place }\end{array}$ & $\begin{array}{l}\text { To identify if } \\
\text { the park could } \\
\text { be a popular } \\
\text { place among } \\
\text { the local } \\
\text { community }\end{array}$ & $\begin{array}{l}\text { A player is a local citizen who is asked } \\
\text { to walk around the park and mark ten } \\
\text { places where he would like to spend } \\
\text { time with his friends and family. } \\
\text { A score of } 100 \text { is granted for fully } \\
\text { completing the task. }\end{array}$ & None & $\begin{array}{l}\text { Player movement paths. } \\
\text { Time spent in the scenario. } \\
\text { Coordinates of the marked } \\
\text { places. }\end{array}$ \\
\hline $\begin{array}{l}\text { S4. } \\
\text { Open } \\
\text { Question }\end{array}$ & $\begin{array}{l}\text { To determine } \\
\text { where in the } \\
\text { park is the } \\
\text { best place for } \\
\text { community } \\
\text { events }\end{array}$ & $\begin{array}{l}\text { A player is a park visitor who is asked } \\
\text { to answer two closed questions and } \\
\text { one open question about the best place } \\
\text { for the community events in this area. } \\
\text { A score of } 100 \text { is granted for fully } \\
\text { completing the task. }\end{array}$ & $\begin{array}{l}\text { People that are walking } \\
\text { around the place of the } \\
\text { community event }\end{array}$ & $\begin{array}{l}\text { Player movement paths. } \\
\text { Time spent in the scenario. } \\
\text { Player answers to the } \\
\text { questions. }\end{array}$ \\
\hline
\end{tabular}


groups of 15 participants played the game in the same room simultaneously, they were asked to play individually, without the discussions between each other. This requirement was needed to increase the variety and the reliability of collected data (Christopherson, 2007). At the end of the experiment, all the data recorded in the game database were processed in order to automatically derive the numeric values of the criteria predetermined to identify the trustworthiness of the players. These values for each of the respondent are presented in Table 3.

The constructed decision matrix was used to determine the trustworthiness of the respondents. The novel PROMETHEE-MGQNN approach was applied to obtain the trustworthiness index $T_{i}(n)$ for each participant $n$. The methodology presented in Section 1.2. was used to calculate the trustworthiness index which is equal to the Score value of the analysed alternative (Eqn (15)). In this study case, each respondent is represented by a different alternative. To show the applicability of the MGQNN sets, the values $m=1$ and $q=3$ were chosen for $m$-generalized q-neutrosophic numbers. These values correspond to the case of the fermatean neutrosophic sets (Senapati \& Yager, 2020).

In this research, we sought to divide the game-based survey respondents into trustworthy and untrustworthy ones. For this purpose, based on the analysis of the possible outliers, the threshold value $\delta=-0.1$ was determined by the field experts. If the participant's trustworthiness index is less than $\delta$, we consider him to be untrustworthy, and vice versa. This threshold value has been determined after mapping the results presented in Figure 5 and the behavioural analysis of the GBS participants. For this purpose, GIS-based data visualisation representing the performance of randomly chosen 12 reliable and non-reliable respondents was done. The connection between the calculated trustworthy index and the behavioural attitude of the specific GBS players has been analysed for this purpose.

Data extracted from Scenario 1 reveals that $98 \%$ of the respondents completed this scenario by marking three hiding locations. However, the decision based solely on the score might be misleading. For instance, analysis of Figure 6 shows that respondent identified as ID42 (trustworthiness -0.5940 ) marked all the hiding positions close to the initial starting position. Participant ID77 (trustworthiness -0.1725) also shows suspicious behaviour as his movement trajectory traverses ponds of the park.

Data extracted from Scenario 2 disclosed that 95\% of the respondents completed it and marked the most attractive place of the park and two other places with the biggest potential to be the most popular among the tourists and among the residents (three places in total). Data analysis revealed that at this level, the average time spent exploring the territory of the park decreased. The behaviour of the GBS players also enlightened some signs of decreasing motivation and increasing untrustworthiness. For instance, while the behaviour of the respondent ID42 (trustworthiness -0.5940) remains questionable (Figure 7),
Table 3. Decision matrix constructed from the in-game data representing the behaviour of the GBS respondents

\begin{tabular}{|c|c|c|c|c|c|c|c|c|c|c|c|}
\hline ID & $\mathrm{C} 1$ & C2 & $\mathrm{C} 3$ & C4 & C5 & ID & C1 & C2 & C3 & $\mathrm{C} 4$ & C5 \\
\hline 1 & 689 & 405 & 0 & 2.07 & 0 & 44 & 1596 & 490 & 6 & 1.34 & 500 \\
\hline 2 & 490 & 482 & 0 & 1.38 & 230 & 45 & \begin{tabular}{|l|l}
1038 \\
\end{tabular} & 863 & 4 & 0.78 & 400 \\
\hline 3 & 1933 & 1187 & 58 & 0.98 & 450 & 46 & 941 & 713 & 12 & 0.88 & 400 \\
\hline 4 & \begin{tabular}{|l|}
1348 \\
\end{tabular} & 757 & 8 & 0.93 & 430 & 47 & 1028 & 726 & 26 & \begin{tabular}{|l|l}
0.89 \\
\end{tabular} & 400 \\
\hline 5 & 1765 & 916 & 12 & 0.72 & 400 & 48 & 913 & 638 & 8 & 0.96 & 400 \\
\hline 6 & 2199 & 994 & 31 & 0.75 & 400 & 49 & 858 & 659 & 8 & 0.94 & 430 \\
\hline 7 & \begin{tabular}{|l}
1357 \\
\end{tabular} & 759 & 14 & 0.82 & 400 & 50 & 856 & 487 & 19 & 1.38 & 400 \\
\hline 8 & \begin{tabular}{|l|}
1431 \\
\end{tabular} & 672 & 19 & 0.96 & 400 & 51 & 970 & 900 & 0 & 0.67 & 400 \\
\hline 9 & 3014 & 1396 & 7 & 0.59 & 450 & 52 & 375 & 285 & 7 & 2.16 & 400 \\
\hline 10 & 2153 & 1149 & 15 & 0.53 & 500 & 53 & 898 & 737 & 2 & 0.88 & 400 \\
\hline 11 & 1333 & 463 & 25 & 1.41 & 400 & 54 & 908 & 675 & 7 & 1.03 & 330 \\
\hline 12 & 958 & 723 & 0 & 0.84 & 300 & 55 & 896 & 702 & 8 & 0.94 & 430 \\
\hline 13 & 979 & 693 & 10 & 0.89 & 400 & 56 & 770 & 626 & 4 & 1.04 & 290 \\
\hline 14 & 1494 & 1087 & 12 & 0.67 & 400 & 57 & \begin{tabular}{|c|}
908 \\
\end{tabular} & 598 & 6 & 1.01 & 400 \\
\hline 15 & 914 & 538 & 18 & 1.12 & 400 & 58 & 825 & 601 & 10 & 1.00 & 430 \\
\hline 16 & 1664 & 976 & 11 & 0.70 & 700 & 59 & 754 & 595 & 11 & \begin{tabular}{|l|}
1.29 \\
\end{tabular} & 580 \\
\hline 17 & 410 & 267 & 0 & 1.50 & 200 & 60 & 562 & 390 & 4 & 1.74 & 400 \\
\hline 18 & 927 & 578 & 0 & 1.05 & 300 & 61 & 731 & 547 & 3 & 1.11 & 400 \\
\hline 19 & 556 & 449 & 0 & 1.40 & 400 & 62 & 847 & 608 & 24 & 1.06 & 430 \\
\hline 20 & 1268 & 725 & 27 & 0.87 & 700 & 63 & 616 & 359 & 9 & 1.86 & 450 \\
\hline 21 & 1061 & 525 & 10 & 1.23 & 500 & 64 & 909 & 788 & 10 & \begin{tabular}{|l|l}
0.83 \\
\end{tabular} & 400 \\
\hline 22 & \begin{tabular}{|l|l|}
1069 \\
\end{tabular} & 732 & 17 & 0.83 & 500 & 65 & 568 & 357 & 5 & \begin{tabular}{|l|}
1.72 \\
\end{tabular} & 400 \\
\hline 23 & 54 & 2 & 0 & 1.45 & 200 & 66 & 9 & 513 & 5 & 1.17 & 400 \\
\hline 24 & 775 & 486 & 9 & 0.93 & 400 & 67 & 808 & 689 & 4 & \begin{tabular}{|l|}
0.88 \\
\end{tabular} & 400 \\
\hline 25 & 142 & 732 & 5 & 0.84 & 400 & 68 & 824 & 664 & 7 & \begin{tabular}{|l|}
0.92 \\
\end{tabular} & 400 \\
\hline 26 & 494 & 285 & 0 & 0.80 & 100 & 69 & 979 & 595 & 4 & 1.05 & 500 \\
\hline 27 & 1483 & 835 & 0 & 0.89 & 500 & 70 & 950 & 582 & 16 & 1.08 & 430 \\
\hline 28 & 1027 & 627 & 0 & 0.96 & 500 & 71 & 707 & 545 & 26 & 1.23 & 400 \\
\hline 29 & 2649 & 816 & 61 & 0.80 & 430 & 72 & 879 & 656 & 8 & \begin{tabular}{|l}
0.94 \\
\end{tabular} & 400 \\
\hline 30 & 2913 & 1277 & 21 & 0.52 & 600 & 73 & 799 & 663 & 4 & 1.09 & 560 \\
\hline 31 & 1015 & 575 & 17 & 1.11 & 500 & 74 & 533 & 414 & 5 & 1.45 & 400 \\
\hline 32 & 278 & 258 & 0 & 1.49 & 200 & 75 & 822 & 560 & 12 & 1.16 & 400 \\
\hline 33 & 809 & 554 & 6 & 1.13 & 400 & 76 & 483 & 354 & 6 & 1.83 & 430 \\
\hline 34 & 1139 & 717 & 4 & 0.86 & 600 & 77 & 459 & 302 & 14 & 2.26 & 400 \\
\hline 35 & 1884 & 636 & 36 & 0.95 & 430 & 78 & 864 & 702 & 16 & 0.98 & 400 \\
\hline 36 & 732 & 282 & 7 & 2.23 & 500 & 79 & 548 & 440 & 6 & 1.49 & 360 \\
\hline 37 & 128 & 122 & 0 & 3.55 & 200 & 80 & 501 & 487 & 0 & 1.56 & 260 \\
\hline 38 & 638 & 387 & 0 & 1.63 & 300 & 81 & 584 & 421 & 5 & 2.05 & 400 \\
\hline 39 & 606 & 487 & 3 & 1.36 & 500 & 82 & 1176 & 814 & 0 & 1.54 & 430 \\
\hline 40 & 347 & 339 & 0 & 1.80 & 250 & 83 & 842 & 799 & 0 & 0.85 & 300 \\
\hline 41 & 505 & 292 & 4 & 2.60 & 390 & 84 & 646 & 404 & 9 & 1.51 & 400 \\
\hline 42 & 247 & 166 & 3 & 3.65 & 380 & 85 & 916 & 667 & 1 & 1.04 & 450 \\
\hline 43 & 417 & 288 & 3 & 2.58 & 400 & 86 & 793 & 486 & 7 & 1.46 & 400 \\
\hline
\end{tabular}

respondents ID76 (trustworthiness -0.1249) and ID77 (trustworthiness -0.1725 ) also started to show the signs of speeding behaviour. Moreover, participant ID76 has marked two locations at the same position at the end of its movement path. Such suspicious actions certainly reduce the overall trustworthiness of the respondents. 


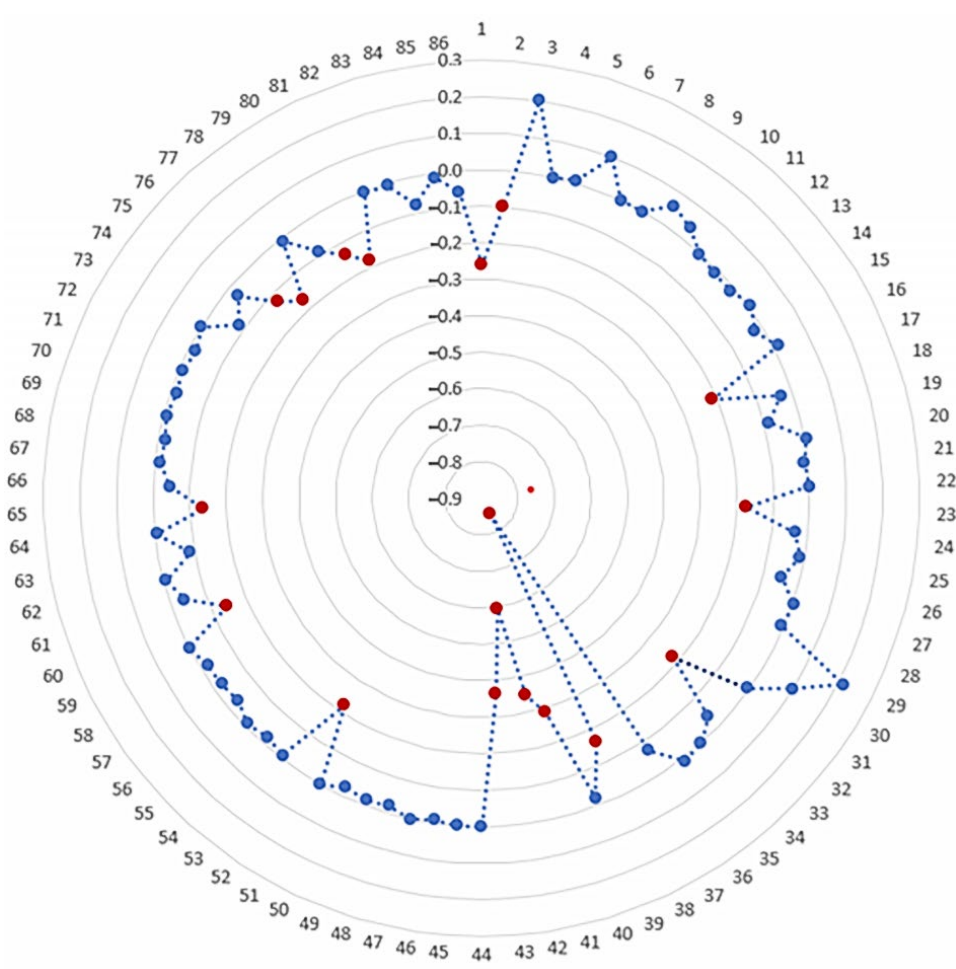

\begin{tabular}{|c|c|c|c|c|c|}
\hline$n$ & $T_{i}(n)$ & $n$ & $T_{i}(n)$ & $n$ & $T_{i}(n)$ \\
\hline 1 & -02625 & 31 & -00056 & 61 & -0.0393 \\
\hline 2 & -0.1021 & 32 & -0.2184 & 62 & -0.0066 \\
\hline 3 & 0.2032 & 33 & -0.0371 & 63 & -0.0875 \\
\hline 4 & 0.0001 & 34 & 0.0016 & 64 & -0.0043 \\
\hline 5 & 0.0078 & 35 & 0.0107 & 65 & -0.1358 \\
\hline 6 & 0.1005 & 36 & -0.0700 & 66 & -0.0443 \\
\hline 7 & 0.0003 & 37 & -0.8500 & 67 & -0.0156 \\
\hline 8 & -0.0002 & 38 & -0.1600 & 68 & -0.0187 \\
\hline 9 & 0.0588 & 39 & -0.0216 & 69 & -00079 \\
\hline 10 & 0.0361 & 40 & -02848 & 70 & -0.0164 \\
\hline 11 & -0.0034 & 41 & -0.3459 & 71 & -0.0093 \\
\hline 12 & -0.0112 & 42 & -05940 & 72 & -0.0187 \\
\hline 13 & -0.0114 & 43 & -0.3605 & 73 & -0.0018 \\
\hline 14 & 0.0079 & 44 & 0.0000 & 74 & -0.0838 \\
\hline 15 & -0.0221 & 45 & 0.0000 & 75 & -0.0336 \\
\hline 16 & 0.0148 & 46 & -0.0097 & 76 & -0.1249 \\
\hline 17 & -0.2101 & 47 & 0.0001 & 77 & -0.1725 \\
\hline 18 & -0.033 & 48 & -00201 & 78 & -0.0108 \\
\hline 19 & -0.0845 & 49 & -0.0150 & 79 & -0.0899 \\
\hline 20 & 0.006 & 50 & -0.0250 & 80 & -0.1388 \\
\hline 21 & -0.0093 & 51 & 0.0006 & 81 & -0.1832 \\
\hline$\overline{22}$ & -0.0001 & 52 & -0.2206 & 82 & -0.0029 \\
\hline 23 & -0.1719 & 53 & -0.0093 & 83 & -0.0057 \\
\hline 24 & -0.0353 & 54 & -0.0200 & 84 & -0.0752 \\
\hline 25 & -0.0118 & 55 & -0.0105 & 85 & -0.0122 \\
\hline 26 & -0.0492 & 56 & -00318 & 86 & -00591 \\
\hline 27 & 0.0038 & 57 & -0.0258 & & \\
\hline 28 & -0.0054 & 58 & -0.0212 & & \\
\hline 29 & 0.216 & 59 & -0.0010 & & \\
\hline 30 & 01012 & 60 & -0.1420 & & \\
\hline
\end{tabular}

Figure 5. Trustworthiness index $T_{i}(n)$ of the respondents calculated by applying the proposed PROMETHEE-MGQNN method

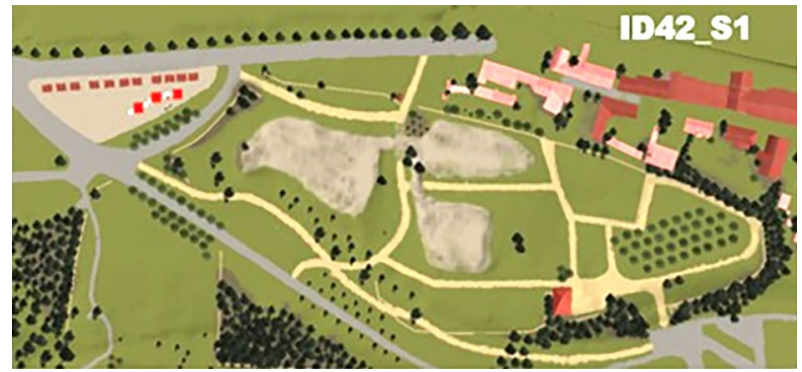

Trustworthiness (ID42) $=-0.5940$

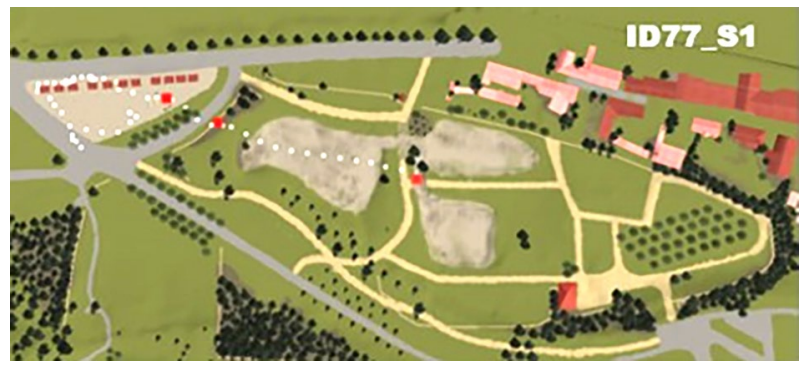

Trustworthiness $($ ID77) $=-0.1725$

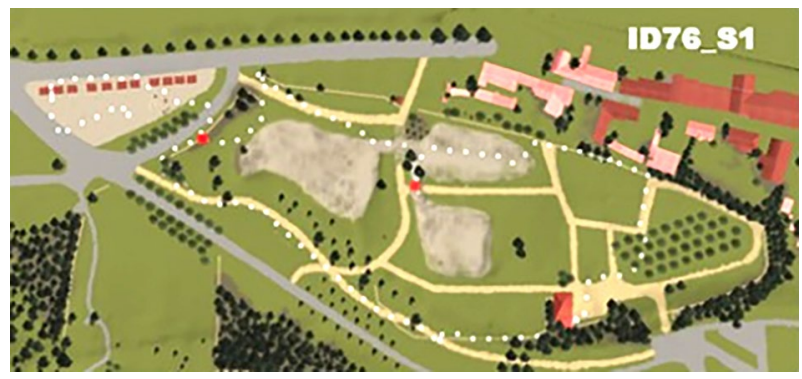

Trustworthiness (ID76) $=-0.1249$

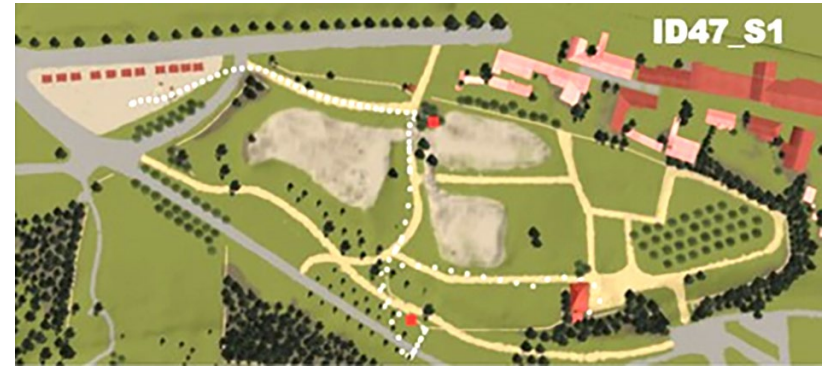

Trustworthiness $($ ID47) $=0.0001$

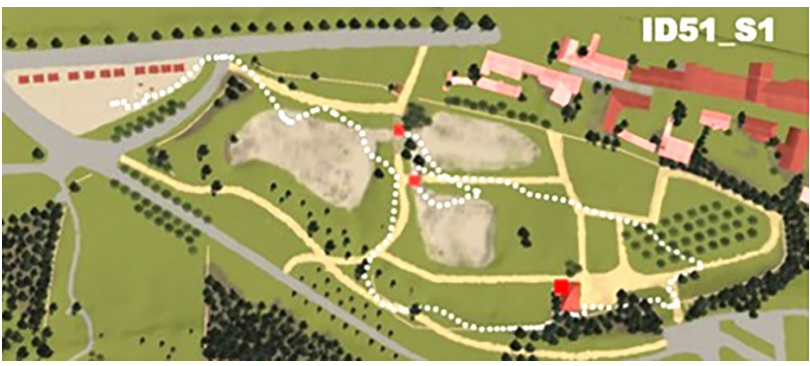

Trustworthiness $($ ID51) $=0.0006$

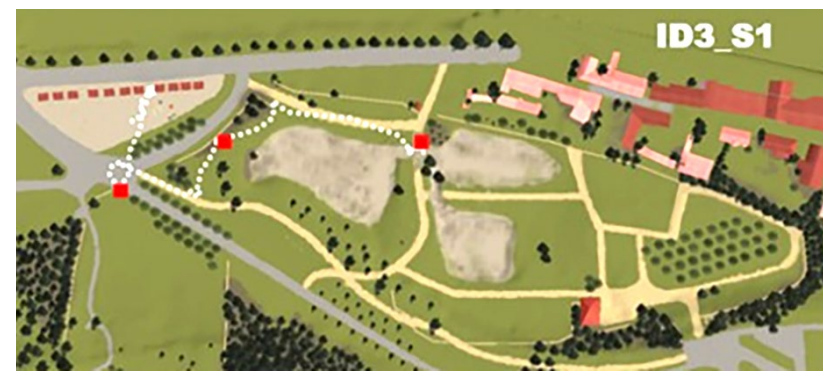

Trustworthiness $($ ID3) $=0.2032$

Figure 6. The behaviour of the selected respondents that played Scenario 1 in the gamified survey "Parkis" 


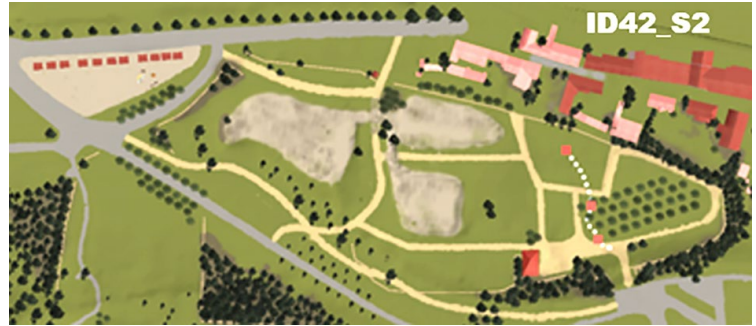

Trustworthiness $($ ID 42$)=-0.5940$

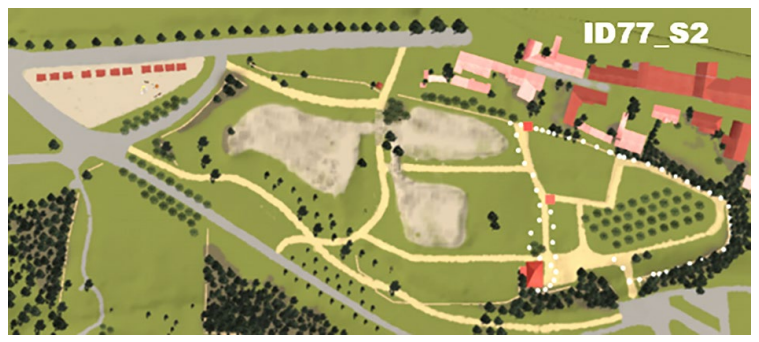

Trustworthiness $($ ID77) $=-0.1725$

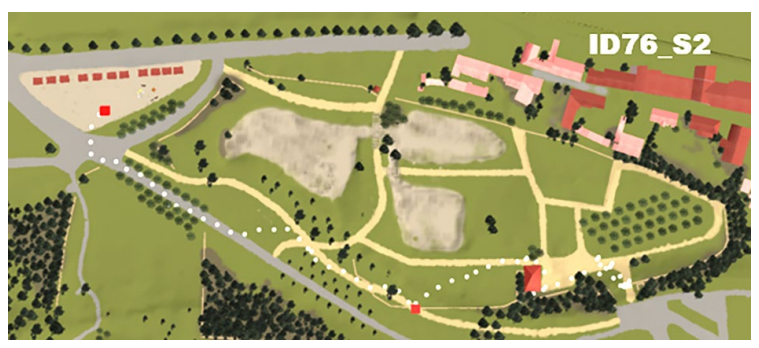

Trustworthiness $($ ID76) $=-0.1249$

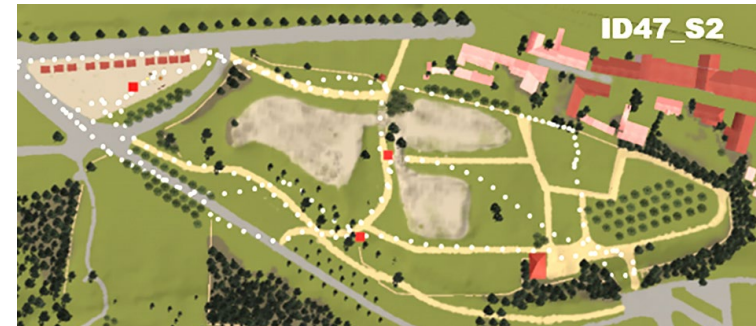

Trustworthiness $($ ID47) $=0.0001$

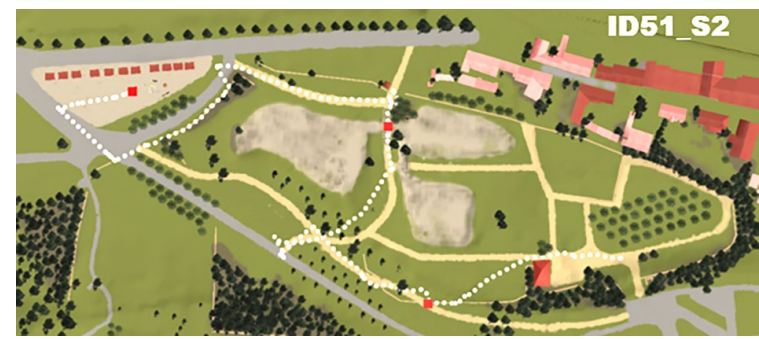

Trustworthiness $($ ID51) $=0.0006$

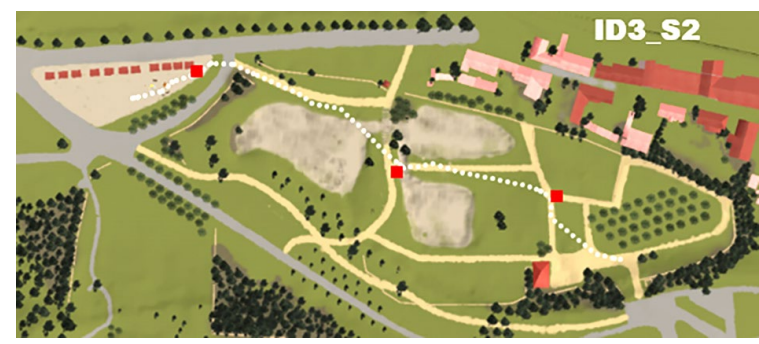

Trustworthiness $($ ID3 $)=0.2032$

Figure 7. The behaviour of the selected respondents that played Scenario 2 in the game-based survey PARKIS

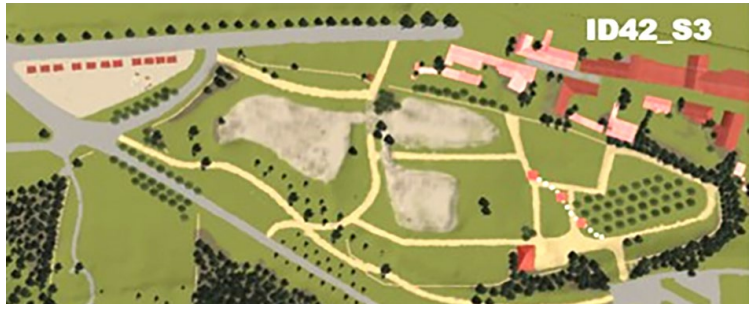

Trustworthiness $($ ID42) $=-0.5940$

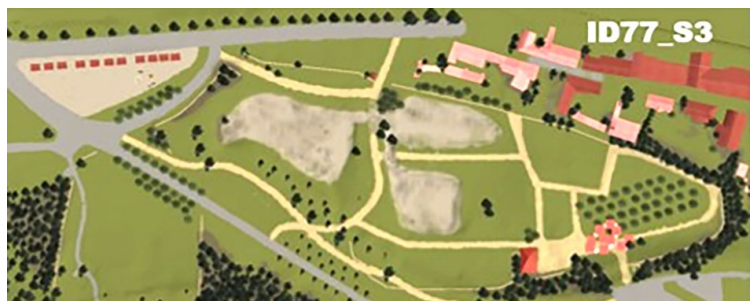

Trustworthiness $($ ID77) $=-0.1725$

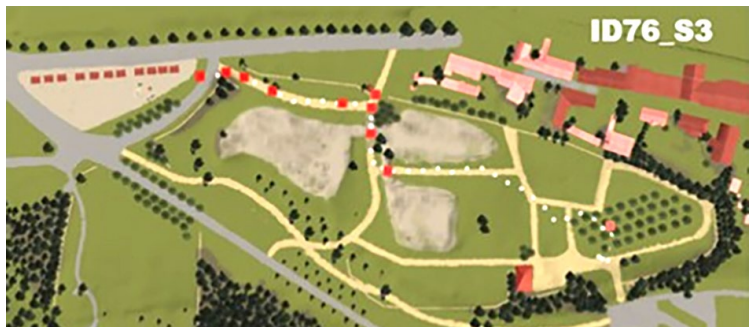

Trustworthiness $($ ID76) $=-0.1249$

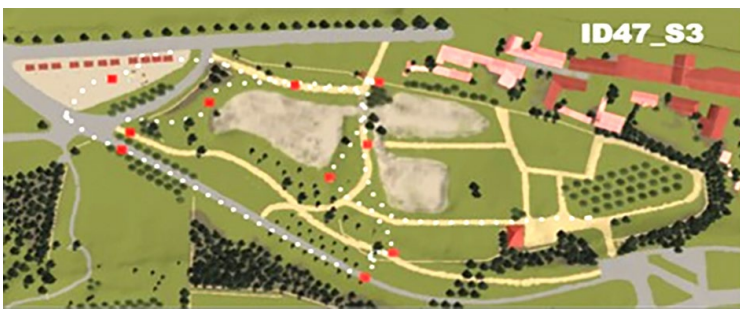

Trustworthiness $($ ID47) $=0.0001$

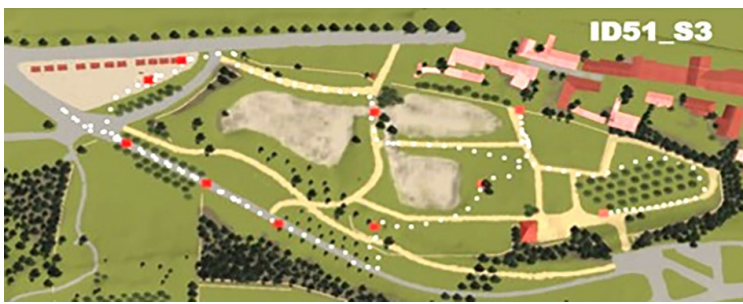

Trustworthiness $($ ID51) $=0.0006$

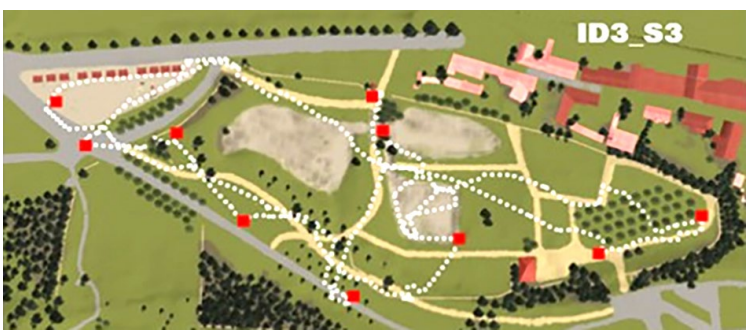

Trustworthiness $($ ID3 $)=0.2032$

Figure 8. The behaviour of the selected respondents that played Scenario 3 in the game-based survey "Parkis" 
Data extracted from Scenario 3 disclosed that the completion rate of this level decreased to $91 \%$. The behavioural analysis of six selected respondents (Figure 8) showed that the player identified as ID42 is systematically unreliable (trustworthiness -0.5940). The same reflection was made about the respondent ID77 (trustworthiness -0.1725), who marked all ten locations by walking in a circle in the same area. The behaviour of respondent ID76 (trustworthiness -0.1249) also remains questionable, as it seems that all ten locations were marked along the respondent's movement path regardless of the task presented in Scenario 3. Experts also noted that suspicious behaviour is the most typical to the respondents with the trustworthiness index smaller than the threshold value $\delta=-0.1$. Erratic behaviour was less common among the GBS players whose trustworthy index was above -0.1 .

\section{Results and discussion}

Data cleaning and validation is an important part of survey-based decision-making techniques. If data satisfies the requirement of accuracy, integrity, completeness, validity, consistency, uniformity, density and uniqueness, they can be treated as high-quality data. However, data cleaning is a challenging process since diverging aspects like the chosen data acquisition strategy, reliability of the participants, and the criteria set determined to detect inaccurate, incomplete and untrustworthy records significantly affect data quality. Data cleaning in the game-based surveys is even more challenging since the in-game behaviour of the GBS respondents must be analysed to ensure the reliability of the extracted information.

In this paper, we proposed to employ multicriteria decision-making theory to analyse the reliability of the respondents who were invited to assess urban public park safety and attractiveness using the game-based survey called "Parkis". Eighty-six persons participating in this experiment marked 254 positions as hiding places. Visual analysis of the collected data revealed that some of these places are marked under the bridges or even in the park's ponds. It was a clear sign that some of the participants are untrustworthy and might cause high inaccuracies in the following steps of the GBS based public space planning (Figure 1). Application of the PROMETHEE-MGQNN allowed us to take into consideration the uncertainties associated with the reliability of the GBS participants. Five criteria that can be automatically calculated from the data recorded during the gameplay were determined to calculate the trustworthiness index proposed to divide GBS participants into reliable and unreliable ones. Based on this index, we found out that $20.93 \%$ of the persons that were invited to assess the safety and attractiveness of the virtual public park "Missionary Garden" were identified as untrustworthy. Identification of these respondents allowed us to exclude their records from the collected data. In this way, many hiding places marked inside the ponds or open spaces were eliminated from further data analysis processes. The final concentration areas of the hiding places and the attraction places are visualised in Figure 9. Data extracted from Scenario 1 and Scenario 2 were used for this purpose.

According to the Crime Prevention Through Environment Design (CPTED) strategy, hiding places might be the reason for the increased insecurity in the urban public parks (Zavadskas et al., 2019b). Therefore, attraction points play an important part in safety insurance. It can be observed in Figure 9 that there are five areas where are no attraction points around the hiding places (these potentially unsafe areas are marked and zoomed in). The potentially insecure locations are at the back of the orchard, near the restored historic buildings and in the areas dense with trees. As these locations can be used for public nuisances (i.e., for alcohol or drugs usage), it was recommended for the decision-maker to pay attention to these areas.

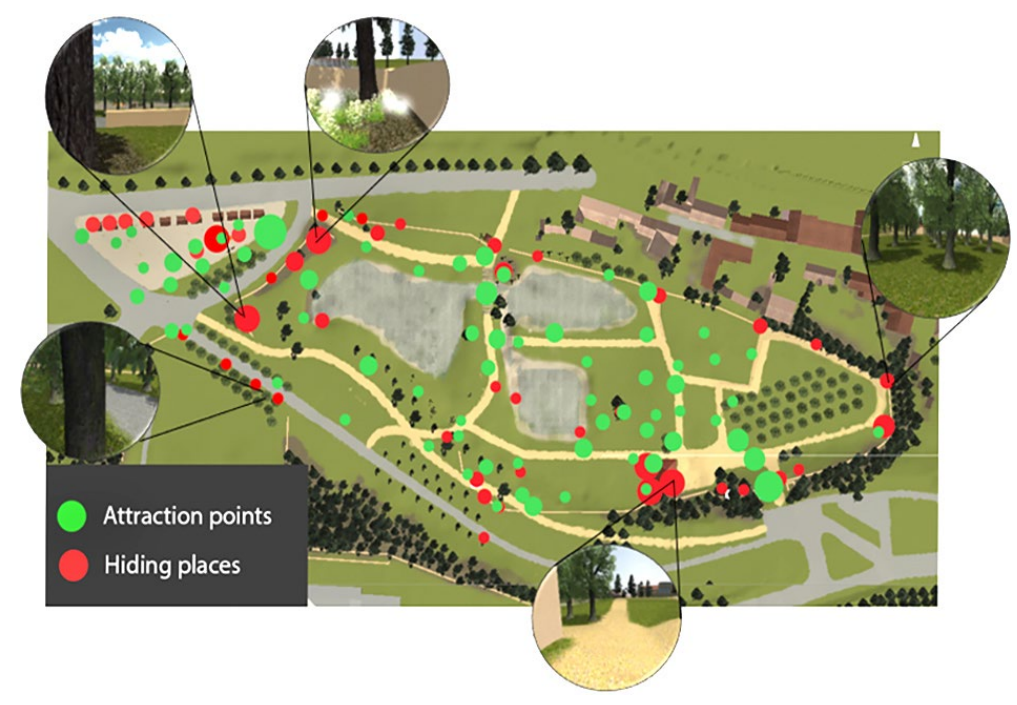

Figure 9. Concentration points of the hiding places and the attraction places of the virtual urban park "Missionary Garden". The size of the markers corresponds to the amount of the points detected in the neighbourhood coordinates 
However, it must be said that the lack of details in the proposed renovation project does not allow GBS developers to construct the ideal representation of the "Missionary Garden”. Since park signs, lights, benches, litters are also important for the urban public park's safety, and they were not presented in the renovation project, there might be some biases in the results obtained by the constructed game-based survey. However, since gamified or game-based surveys are much more attractive for the people who do not have specialized knowledge on the urban planning processes, this type of the participatory tools are much more recommended for the citizens' involvement in the decision-making processes.

\section{Conclusions}

Serious games and game-based surveys offer an engaging way to increase citizens participation in the urban planning processes. However, there is always the risk that some of the participants are not motivated to take the survey seriously or reject game-alike solutions as an inappropriate tool to collect public opinions. While data recorded from this type of respondents might decrease the overall reliability of the game-based decision-making approaches, identification of the untrustworthy GBS participants is becoming of significant importance.

In response to the determined problem, the novel multicriteria decision-making approach PROMETHEE under the m-generalised q-neutrosophic numbers (PROMETHEE-MGQNN) was proposed in this paper. The authors of this study also presented five numerically measurable criteria to identify the trustworthiness of the citizens participating in the games-based surveys dedicated to exploring the peculiarities (particularly, safety and attractiveness) of the real-world geographical areas. While the presented approach can deal with the uncertainties of initial information raised by neuropsychology of the GBS participants, it can also be considered as the specific data cleaning and validation methodology.

The game-based survey "Parkis" developed to assess the safety and attractiveness of the urban public park "Missionary Garden" (Vilnius, Lithuania) was created and employed to analyse the practicalities of the proposed methodology. The novel PROMETHEE-MGQNN approach was applied to analyse data collected from 86 citizens invited to participate in the experiment. Calculation of the trustworthy index aided to discover that $20.93 \%$ of the GBS players might be untrustworthy. Visual analysis of the participants' in-game behaviour approved these results. While the application of the MCDM based data cleaning allowed us to provide decision-makers with a more reliable result about the urban park safety and attractiveness, we believe that the proposed methodology can be successfully transferred to different GBS-based studies. However, it is necessary to note that criteria defined in this study are directly related to the presented scenarios; therefore, the set of parameters predetermined to identify the trustworthiness of GBS participants must be reviewed each time individually.

\section{Funding}

This research did not receive any specific grant from funding agencies in the public, commercial, or not-for-profit sectors.

\section{Author contributions}

R. B.: Conceptualization, Methodology, Validation, Formal analysis, Resources, Writing - Reviewing \& Editing, Supervision, Project administration. I. L.: Conceptualization, Methodology, Validation, Formal analysis, Investigation, Data Curation, Writing - Original Draft, Writing Reviewing \& Editing, Visualisation. R. S.: Conceptualization, Methodology, Software, Validation, Formal analysis, Resources, Writing - Reviewing \& Editing, Visualisation.

\section{Disclosure statement}

Authors in this paper confirm that they do not have any competing financial, professional, or personal interests from other parties.

\section{References}

Alonso, L., Zhang, Y. R., Grignard, A., Noyman, A., Sakai, Y., ElKatsha, M., Doorley, R., \& Larson, K. (2018). Cityscope: a data-driven interactive simulation tool for urban design. use case volpe. In International Conference on Complex Systems (pp. 253-261). https://doi.org/10.1007/978-3-319-96661-8_27

Alonso-Fernández, C., Calvo-Morata, A., Freire, M., MartínezOrtiz, I., \& Fernández-Manjón, B. (2019). Applications of data science to game learning analytics data: a systematic literature review. Computers \& Education, 141, 103612.

https://doi.org/10.1016/j.compedu.2019.103612

Ampatzidou, C., Gugerell, K., Constantinescu, T., Devisch, O., Jauschneg, M., \& Berger, M. (2018) All work and no play? Facilitating serious games and gamified applications in participatory urban planning and governance. Urban Planning, 3, 34-46. https://doi.org/10.17645/up.v3i1.1261

Aubert, A. H., \& Lienert, J. (2019). Gamified online survey to elicit citizens' preferences and enhance learning for environmental decisions. Environmental Modelling \& Software, 111, 1-12. https://doi.org/10.1016/j.envsoft.2018.09.013

Dupuis, J., \& Knoepfel, P. (2015). Concluding discussion: Institutional regime and actors' modes of participation and interaction in environmental decision-making. In The politics of contaminated sites management (pp. 147-158). Springer International Publishing.

https://doi.org/10.1007/978-3-319-11307-4_9

Battista, A. (2017). An activity theory perspective of how scenario-based simulations support learning: A descriptive analysis. Advances in Simulation, 2(1), 23. https://doi.org/10.1186/s41077-017-0055-0

Bausys, R., Kazakeviciute-Januskeviciene, G., Cavallaro, F., \& Usovaite, A. (2020). Algorithm selection for edge detection in satellite images by neutrosophic WASPAS method. Sustainability, 12, 548. https://doi.org/10.3390/su12020548

Berta, R., \& Moreno-Ger, P. (2018). Introduction: Intelligent learning assessment in serious games. International Journal of Serious Games, 5(1), 3-4.

https://doi.org/10.17083/ijsg.v5i1.237 
Beullens, K., Loosveldt, G., Vandenplas, C., \& Stoop, I. (2018). Response rates in the European social survey: Increasing, decreasing, or a matter of fieldwork efforts? Survey methods: Insights from the field. https://surveyinsights.org/?p=9673

Brown, G. (2017). A review of sampling effects and response bias in internet participatory mapping (PPGIS/PGIS/VGI). Transactions in GIS, 21, 39-56. https://doi.org/10.1111/tgis.12207

Chen, L., Xu, Z., Wang, H., \& Liu, S. (2018). An ordered clustering algorithm based on K-means and the PROMETHEE method. International Journal of Machine Learning and Cybernetics, 9, 917-926.

https://doi.org/10.1007/s13042-016-0617-9

Chen, C. T., \& Hung, W. Z. (2020). A two-phase model for personnel selection based on multi-type fuzzy information. Mathematics, 8, 1703. https://doi.org/10.3390/math8101703

Christopherson, K. M. (2007). The positive and negative implications of anonymity in Internet social interactions: "On the Internet, nobody knows you're a dog". Computers in Human Behavior, 23, 3038-3056.

https://doi.org/10.1016/j.chb.2006.09.001

Czepkiewicz, M., Jankowski, P., \& Młodkowski, M. (2017). Geoquestionnaires in urban planning: Recruitment methods, participant engagement, and data quality. Cartography and Geographic Information Science, 44(6), 551-567.

Devisch, O., Poplin, A., \& Sofronie, S. (2016). The gamification of civic participation: Two experiments in improving the skills of citizens to reflect collectively on spatial issues. Journal of Urban Technology, 23(2), 81-102.

https://doi.org/10.1080/10630732.2015.1102419

Irvin, R. A., \& Stansbury, J. (2004). Citizen participation in decision making: is it worth the effort?. Public Administration Review, 64(1), 55-65. https://doi.org/10.1111/j.1540-6210.2004.00346.x

Falco, E., \& Kleinhans, R. (2018). Digital participatory platforms for co-production in urban development: A systematic review. International Journal of E-Planning Research, 7(3), 52-79. https://doi.org/10.4018/IJEPR.2018070105

Følstad, A. (2009). Co-creation through user feedback in an online living lab: A case example. Open design spaces supporting user innovation. In Proceedings of the International Workshop on Open Design Spaces (pp. 43-55). International Institute for SocioInformatics.

Foth, M., Bajracharya, B., Brown, R., \& Hearn, G. (2009). The second life of urban planning? Using neogeography tools for community engagement. Journal of Location Based Services, 3(2: NeoGeography), 97-117.

https://doi.org/10.1080/17489720903150016

Hassan, L., \& Hamari, J. (2020). Gameful civic engagement: A review of the literature on gamification of e-participation. Government Information Quarterly, 37(3), 101461. https://doi.org/10.1016/j.giq.2020.101461

Keim, D., Andrienko, G., Fekete, J. D., Görg, C., Kohlhammer, J., \& Melançon, G. (2008). Visual analytics: Definition, process and challenges. In A. Kerren, J. T. Stasko, J.-D. Fekete, \& C. North (Eds.), Lecture notes in computer science: Vol. 4950. Information visualization (pp. 154-175). Springer. https://doi.org/10.1007/978-3-540-70956-5_7

Keusch, F., \& Zhang, C. (2017). A review of issues in gamified surveys. Social Science Computer Review, 35(2), 147-166. https://doi.org/10.1177/0894439315608451

Lescauskiene, I., Bausys, R., Zavadskas, E. K., \& Juodagalviene, B. (2020). VASMA weighting: Survey-based criteria weighting methodology that combines ENTROPY and WASPAS-SVNS to reflect the psychometric features of the VAS scales. Symmetry, 12, 1641. https://doi.org/10.3390/sym12101641

Loh, C. S., Sheng, Y., \& Ifenthaler, D. (2015). Serious games analytics: Theoretical framework. In C. S. Loh, Y. Sheng, \& D. Ifenthaler (Eds.), Serious games analytics. methodologies for performance measurement, assessment, and improvement (pp. 3-29). Springer. https://doi.org/10.1007/978-3-319-05834-4_1

Mohandes, S. R., Sadeghi, H., Mahdiyar, A., Durdyev, S., Banaitis, A., Yahya, K., \& Ismail, S. (2020). Assessing construction labours' safety level: a fuzzy MCDM approach. Journal of Civil Engineering and Management, 26(2), 175-188. https://doi.org/10.3846/jcem.2020.11926

Munster, S., Georgi, C., Heijne, K., Klamert, K., Noennig, J. R., Pump, M., Stelzle, B., \& van der Meer, H. (2017). How to involve inhabitants in urban design planning by using digital tools? An overview on a state of the art, key challenges and promising approaches. Procedia Computer Science, 112, 2391-2405. https://doi.org/10.1016/j.procs.2017.08.102

Owen, V. E., \& Baker, R. S. (2019). Learning analytics for games. In J. L. Plass, R. Meyer, \& B. D. Homer (Eds.), Handbook of game-based learning. MIT Press.

Papadopoulos, Y., \& Warin, P. (2007), Are innovative, participatory and deliberative procedures in policy making democratic and effective?. European Journal of Political Research, 46(4), 445-472. https://doi.org/10.1111/j.1475-6765.2007.00696.x

Poplin, A. (2012). Playful public participation in urban planning: A case study for online serious games. Computers, Environment and Urban Systems, 36(3), 195-206.

https://doi.org/10.1016/j.compenvurbsys.2011.10.003

Pradhan, S., \& Abdourazakou, Y. (2020). "Power ranking” professional circuit eSports teams using multi-criteria decisionmaking (MCDM). Journal of Sports Analytics, 6, 61-73. https://doi.org/10.3233/JSA-190420

Semenas, R., \& Bausys, R. (2020). Modelling of autonomous search and rescue missions by interval-valued neutrosophic WASPAS framework. Symmetry, 12, 162. https://doi.org/10.3390/sym12010162

Senapati, T., \& Yager, R.R. (2020). Fermatean fuzzy sets. Journal of Ambient Intelligence and Humanized Computing, 11, 663-674. https://doi.org/10.1007/s12652-019-01377-0

Smarandache, F. (2019). Neutrosophic set is a generalization of intuitionistic fuzzy set, inconsistent intuitionistic fuzzy set, pythagorean fuzzy set, q-rung orthopair fuzzy set, spherical fuzzy set and n-hyperbolic fuzzy set while neutrosophication is a generalization of regret theory, grey system theory and three ways decision. Journal of New Theory, 29, 1-35. https://doi.org/10.1002/9781119544203.ch1

Stauskis, G. (2014). Development of methods and practices of virtual reality as a tool for participatory urban planning: a case study of Vilnius City as an example for improving environmental, social and energy sustainability. Energy, Sustainability and Society, $4,7$.

https://doi.org/10.1186/2192-0567-4-7

Urbaniak, K., Wątróbski, J., \& Sałabun, W. (2020). Identification of players ranking in E-Sport. Applied Sciences, 10, 6768. https://doi.org/10.3390/app10196768

Von Winterfeldt, D., \& Edwards, W. (1986). Decision analysis and behavioral research. Cambridge University Press.

Zavadskas, E. K., Bausys, R., Juodagalvienè, B., \& GarnytėSapranavičienė, I. (2017). Model for residential house element and material selection by neutrosophic MULTIMOORA method. Engineering Applications of Artificial Intelligence, 64, 315-324. 
Zavadskas, E. K., Bausys, R., Kaklauskas, A., \& Raslanas, S. (2019a). Hedonic shopping rent valuation by one-to-one neuromarketing and neutrosophic PROMETHEE method. Applied Soft Computing, 85, 105832. https://doi.org/10.1016/j.asoc.2019.105832

Zavadskas, E. K., Bausys, R., \& Mazonaviciute, I. (2019b). Safety evaluation methodology of urban public parks by multicriteria decision making. Landscape and Urban Planning, 189, 372-381. https://doi.org/10.1016/j.landurbplan.2019.05.014

Zavadskas, E. K., Bausys, R., Lescauskiene, I., \& Omran, J. (2020). M-generalised q-neutrosophic MULTIMOORA for decision making. Studies in Informatics and Control, 29(4), 389-398. https://doi.org/10.24846/v29i4y202001

Zavadskas, E. K., Bausys, R., Lescauskiene, I., \& Usovaite, A. (2021). MULTIMOORA under interval-valued neutrosophic sets as the basis for the quantitative heuristic evaluation methodology HEBIN. Mathematics, 9(1), 66. https://doi.org/10.3390/math9010066

Zhang, C., \& Conrad, F. (2014). Speeding in web surveys: The tendency to answer very fast and its association with straightlining. Survey Research Methods, 8(2), 127-135.

https://doi.org/10.18148/srm/2014.v8i2.5453 